\title{
Strain Rate Sensitivity of Superplastic Inconel 718
}

\author{
Marta Urdanpilleta ${ }^{1}$, José Manuel Martínez-Esnaola ${ }^{2}$ and Javier Gil Sevillano ${ }^{2}$ \\ ${ }^{1}$ E.T.S. de Arquitectura, University of the Basque Country, Plaza Oñate 2, San Sebastián 20018, Spain \\ ${ }^{2}$ CEIT and TECNUN (University of Navarra), P. Manuel Lardizábal 15, San Sebastián 20018, Spain
}

The strain rate sensitivity, $m$, of a superplastic-quality (SPF) INCONEL 718 alloy has been measured in the temperature and strain rate ranges of $925-1000^{\circ} \mathrm{C}$ and $10^{-4}-10^{-2} \mathrm{~s}^{-1}$ using both the classical method of instantaneous strain rate changes and a new method based on the continuous response to a sinusoidal strain rate input. The novel method furnishes continuous information from the whole stress-strain curve on the dependence of $m$ on strain rate transients.

In agreement with other recent studies, our results show that the maximum $m$ values of the 718 alloy, although interesting enough for industrial superplastic forming, are lower than those shown by other superplastic materials for typical aeronautical application. A texture analysis indicates that crystallographic slip does not merely act here as an accommodation mechanism for grain boundary sliding. It significantly contributes to the total plastic strain, being thus responsible for the relatively low values observed for the strain rate sensitivity $m$.

(Received March 28, 2005; Accepted May 17, 2005; Published July 15, 2005)

Keywords: superplasticity, superalloy, strain rate changes, transient effects, texture

\section{Introduction}

Superplastic behaviour is conventionally defined as a deformation regime in temperature-strain rate-strain space $(T, \dot{\varepsilon}, \varepsilon)$ where plastic instabilities are delayed or suppressed by a high value of the strain rate sensitivity of the flow stress, $\sigma$. The strain rate sensitivity is usually characterised by the $m$ parameter,

$$
m=\frac{\dot{\varepsilon}}{\sigma} \frac{\partial \sigma}{\partial \dot{\varepsilon}} \approx \frac{\dot{\varepsilon} \Delta \sigma}{\sigma \Delta \dot{\varepsilon}}
$$

obtained from intermittent -nominally instantaneouschanges between two strain rates during tensile tests performed at a constant temperature. Because of the necessity of discarding the stress-strain transients that appear after a finite strain rate change, only several discrete values of $m$ can be obtained from each test. Thus a method to measure $m$ based on continuous strain rate changes would be very appealing. Moreover, in real superplastic forming operations of complex shapes, the variations in local strain rates with time are continuous instead of stepped. A possible dependence of $m$ on the rate of strain rate change, $\ddot{\varepsilon}$ (hereafter, the strain acceleration), should not be excluded although to our knowledge it has never been studied. Properly assessing such dependence could be important for better monitoring superplastic processes of difficult-to-form materials, such as Nickel-based superalloys for aerospace applications.

This paper explores the applicability to the characterisation of superplasticity of a method firstly proposed by Ling et $a l .{ }^{1)}$ for the study on the strain rate sensitivity of strainageing alloys. The method is based on obtaining $m(\varepsilon, \dot{\varepsilon}, \ddot{\varepsilon}, T)$ from tensile tests in which a sinusoidal perturbation is imposed to a nominally constant strain rate, $\dot{\varepsilon}$. By performing the tests with different frequencies, a wide range of "strain accelerations", $\ddot{\varepsilon}$, can be covered. The conventional $m$ value obtained from instantaneous strain rate changes can also be obtained from the strain rate modulated tests by extrapolation of the results to $\ddot{\varepsilon} \rightarrow \infty$. Another analysis of the results can also be performed in terms of the amplitude and phase lag of the flow stress response as a function of the frequency of the applied strain rate signal.

The proposed method has been applied to the characterisation of an INCONEL ${ }^{\circledR} 718$ SPF Nickel superalloy for which conventional instantaneous strain rate tests have also been performed (INCONEL and 718SPF are trade marks of Inco International Industries).

The excellent mechanical and antioxidation properties of INCONEL 718 at temperatures as high as $650^{\circ} \mathrm{C}$ have made of this alloy the "workhorse" material for gas turbine industries. As a consequence, many studies on its hotworkability $^{2-10)}$ and its potential superplasticity ${ }^{1-19)}$ have been published in recent years. However, further systematic investigations are still needed, because the superplastic properties reached up to now by fine grained INCONEL 718 , such as elongation to fracture or strain rate sensitivity are still modest if compared to the corresponding values of superplastic-grade titanium and aluminium alloys. The maximum values of strain rate sensitivity $m$ reported in the literature are low for the strain rates of industrial interest. For instance, Smith et al. ${ }^{11)}$ and Huang et al. ${ }^{12,18)}$ have found peak $m$ values of about 0.4 only when the strain rate is reduced to $10^{-4} \mathrm{~s}^{-1}$ or below. Moreover, they have observed the evidence of a major role of dislocation creep in the deformation, to the detriment of grain boundary sliding, even under such conditions. Grain boundary sliding (accommodated by other mechanisms) is commonly accepted to be responsible for the high values of the strain rate sensitivity $(m \geq 0.5)$ and therefore for the stability of the flow of finegrained "true" superplastic materials. Very rarely peak values near 0.5 have ever been reported for fine grained 718 alloy. The quoted authors consider the 718SPF alloy behaves as only "near-superplastic", i.e., at the borderline between "true" superplastic and normal slip based deformation.

\section{Material and Experimental Procedure}

The chemical composition of the $1 \mathrm{~mm}$ thick INCONEL 718 SPF sheet employed in this study is given in Table 1 . The material, supplied by Inco Alloys International (Huntington, 
Table 1 Chemical composition (mass percent) of INCONEL 718SPF studied.

\begin{tabular}{ccccccccc}
\hline $\mathrm{C}$ & $\mathrm{Ti}$ & $\mathrm{Mn}$ & $\mathrm{Co}$ & $\mathrm{Fe}$ & $\mathrm{Mo}$ & $\mathrm{S}$ & $\mathrm{Nb}$ & $\mathrm{Si}$ \\
\hline 0.02 & 0.95 & $<0.01$ & $<0.01$ & 18.58 & 3.03 & 0.0018 & 4.95 & $<0.01$ \\
\hline $\mathrm{Ta}$ & $\mathrm{Cu}$ & $\mathrm{P}$ & $\mathrm{Ni}$ & $\mathrm{B}$ & $\mathrm{Cr}$ & $\mathrm{N}$ & $\mathrm{Al}$ \\
\hline 0.01 & $<0.01$ & 0.003 & 53.65 & 0.003 & 18.22 & 0.01 & 0.52 \\
\hline
\end{tabular}

Virginia, USA), a fine-grain grade of the 718 alloy, was intended for superplastic forming and it was kindly provided by ITP (Industria de Turbo Propulsores), Zamudio, Spain.

For metallographic observations, the material was electroetched at room temperature in the reagent composed of $10 \mathrm{~g}$ oxalic acid in $100 \mathrm{ml}$ water. Etching time was about $20 \mathrm{~s}$ at a voltage of $6 \mathrm{~V} \mathrm{DC}$.

The texture of the as-received material was measured by X-Ray diffraction (Philips X'Pert MRD goniometer, MTMFHM v.2 ODF analysis software) and by EBSD (TSL OIM in a Philips XL-30-CP SEM). The agreement of the X-Ray and EBSP ODFs was very good. The textures of the deformed samples were measured only by the EBSP technique.

The microstructure of the as-received material is shown in Fig. 1. Grains are equiaxed, and some grain size heterogeneity is evident. Grain size, measured by the linear intercept method and averaged over the three principal directions of the sheet (geometrical average) was $5.0 \pm$ $0.3 \mu \mathrm{m}$ (95\% confidence level).

Tensile specimens with gauge length of $30 \mathrm{~mm}$ and width of $10 \mathrm{~mm}$ were tested in an Instron 8562 screw-driven machine under protective Argon atmosphere. The crosshead speed was computer-controlled in order to obtain the desired true strain rates calculated on the basis of the total original gauge length assuming constant volume elongation (no extensometer was used). At the low velocities used, the difference between the target crosshead speed and the one actually achieved by the machine was negligible.

The apparent or measured strain rate can be decomposed in several terms:

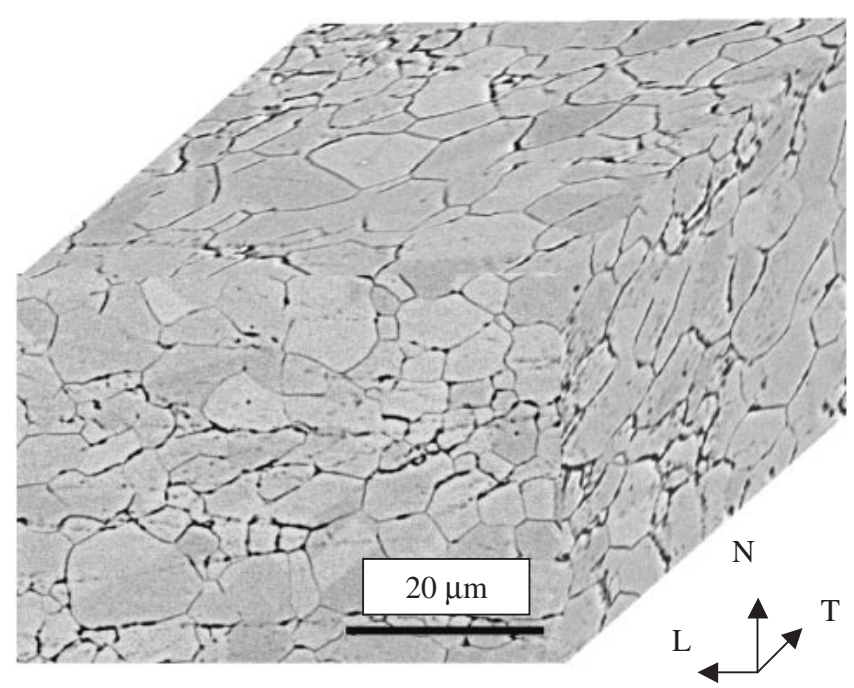

Fig. 1 Microstructure of the as-received material. SEM micrograph, primary electrons.

$$
\dot{\varepsilon}_{\text {app }}=\dot{\varepsilon}_{\text {El,sample }}+\dot{\varepsilon}_{\text {lnel,sample }}+\dot{\varepsilon}_{\text {El,machine }}
$$

where $\dot{\varepsilon}_{\mathrm{El} \text {,sample }}$ refers to the elastic strain rate at which the sample deforms, $\dot{\varepsilon}_{\text {lnel,sample }}$ is the inelastic strain rate of the sample, which includes plastic and anelastic contributions, and $\dot{\varepsilon}_{\mathrm{El} \text {,machine }}$ is the elastic strain rate contribution from the machine.

The effects of machine stiffness (third term in eq. 2) have been neglected, taking into account the low loads and speeds imposed and the high rigidity of the machine frame and trainload employed. The term of elastic strain rate of the sample was also neglected, as this term was calculated to be two orders of magnitude lower than the inelastic part.

Prior to testing, the samples were maintained for $30 \mathrm{~min}$. at the test temperature. The precision of the temperature control was better than $\pm 3^{\circ} \mathrm{C}$. Although the thermal conductivity of the material is relatively low, no adiabatic corrections were made, because of the low strain rates studied $\left(10^{-4}\right.$ to $\left.10^{-2} \mathrm{~s}^{-1}\right)$.

Two types of tests were carried out. First, tensile tests with repeated "instantaneous" strain rate changes, in which a constant strain rate is imposed with some small intermittent excursions to a $50 \%$ higher strain rate (Fig. 2(a)). The strain rate changes are nominally instantaneous (a step function), and the deformation at the second strain rate is small $(3 \%$ every $12 \%$ strain increment), but higher than the transient that accompanies any sudden strain rate change. With this type of tests, temperatures and strain rates ranging, respectively, from 925 to $1000^{\circ} \mathrm{C}$ and from $10^{-4}$ to $10^{-2} \mathrm{~s}^{-1}$ were employed. Second, tensile tests with continuous variation of strain rate were performed, where an oscillatory (sinusoidal) signal with variable frequency was added to a constant strain rate of $10^{-3} \mathrm{~s}^{-1}$, the amplitude of the oscillation being $50 \%$ of the base strain rate. Nine different frequencies were imposed with periods ranging from 18.75 to $300 \mathrm{~s}$. The
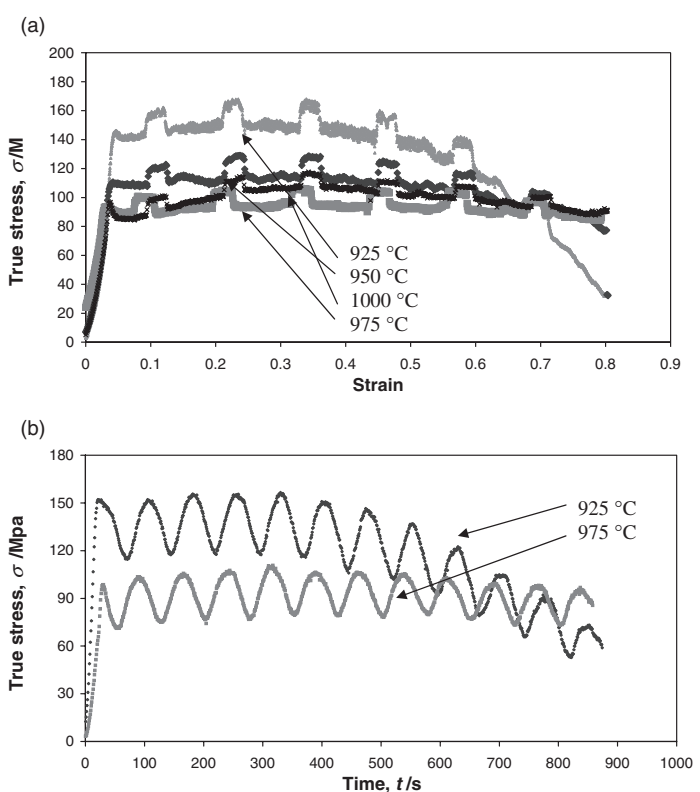

Fig. 2 (a) Instantaneous strain rate change tests, performed at temperatures between 925 and $1000^{\circ} \mathrm{C}$, and base strain rate of $10^{-3} \mathrm{~s}^{-1}$. (b) Tensile tests with continuous variation of the strain rate, at 925 and $975^{\circ} \mathrm{C}$, and a base strain rate of $10^{-3} \mathrm{~s}^{-1}$. 
imposed true strain rate has the form:

$$
\dot{\varepsilon}=\dot{\varepsilon}_{0}+\dot{\varepsilon}_{1} \cos \omega t=\dot{\varepsilon}_{0}\left(1+\frac{1}{2} \cos \omega t\right)
$$

Figure 2 shows some examples of stress-strain plots resulting from both types of tests. A more detailed description of the material and conditions of the tests performed is given in Ref. 20).

\section{Results}

\subsection{Strain rate sensitivity from instantaneous strain rate changes}

The conventional definition of strain rate sensitivity $m$, given in eq. (1), is employed on the assumption that the kinetics of superplastic deformation obeys (at least in the neighbourhood of a set of testing variables) the power-law equation,

$$
\sigma=K \dot{\varepsilon}^{m}
$$

From the response to a strain rate change between two strain rates $\dot{\varepsilon}_{1}$ and $\dot{\varepsilon}_{2}$, when the latter is not too different from $\dot{\varepsilon}_{1}$, the strain rate sensitivity can be obtained by the approximation

$$
m \approx \frac{\ln \left(\sigma_{2} / \sigma_{1}\right)}{\ln \left(\dot{\varepsilon}_{2} / \dot{\varepsilon}_{1}\right)}
$$

where the corresponding flow stresses are the values at each strain rate extrapolated to the instant of the change.

The results obtained in this work using this technique are presented in Fig. 3. A maximum value of $m \approx 0.4$ (i.e., the optimum condition for superplastic formability in the analysed range of processing variables) is found at $975^{\circ} \mathrm{C}$ at a strain rate of $10^{-4} \mathrm{~s}^{-1}$. The strain rate sensitivity drops above $975^{\circ} \mathrm{C}$, in agreement with other published results. ${ }^{18)}$ There is no significant influence of the amount of accumulated strain on $m$ in the deformation range covered by the tests (tests were stopped before rupture at maximum engineering elongations up to $370 \%$ ).

\subsection{Strain rate sensitivity assessed from oscillating strain rate tests}

From the stress-strain-time data obtained from the oscillating strain rate tests, the strain rate sensitivity can be obtained using the following approximation for the total stress rate:

$$
\frac{d \sigma}{d t}=\left.\frac{\partial \sigma}{\partial t}\right|_{\varepsilon, \dot{\varepsilon}}+\left.\frac{\partial \sigma}{\partial \varepsilon}\right|_{\dot{\varepsilon}} \dot{\varepsilon}+\left.\frac{\partial \sigma}{\partial \dot{\varepsilon}}\right|_{\varepsilon} \ddot{\varepsilon}
$$

where higher order terms of the expansion, which reflect the effect of the higher derivatives of the strain on $\sigma$, have been neglected. This simplification is based on the form of the time derivatives of order $p$ of the strain $\varepsilon, d^{p} \varepsilon / d t^{p}$, which vary as $\omega^{p-1}$, see eq. (3). As $\omega<1$ in our tests (ranging approximately between 0.021 and $0.34 \mathrm{rad} / \mathrm{s}$ ) the higher order derivatives of $\varepsilon$ rapidly decay in amplitude.

The term of explicit stress dependence on time, $\partial \sigma /\left.\partial t\right|_{\varepsilon, \dot{\varepsilon}}$, represents the contribution of stress relaxation. If only the plastic and the elastic contributions to the strain rate are taken into account, the relaxation condition leads to:
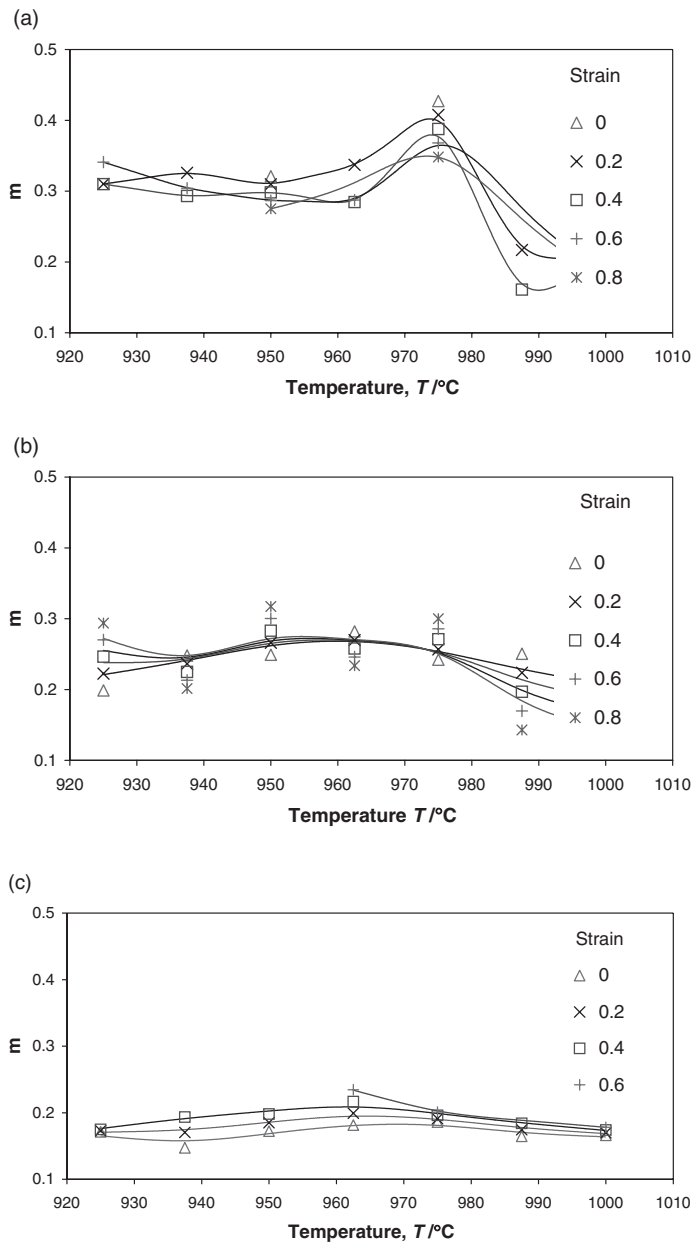

Fig. 3 Strain rate sensitivity versus temperature from instantaneous strain rate change tests. Fitting has been performed with $\beta$-splines. Base strain rates: (a) $10^{-4} \mathrm{~s}^{-1}$, (b) $10^{-3} \mathrm{~s}^{-1}$ and (c) $10^{-2} \mathrm{~s}^{-1}$.

$$
\dot{\varepsilon}=\dot{\varepsilon}_{\mathrm{El}}+\dot{\varepsilon}_{\mathrm{Pl}}=\frac{\dot{\sigma}}{E}+A \sigma^{1 / m}=0
$$

where $E$ is the elastic modulus and $A$ is a constant. Resolving the differential equation, it may be verified that the relaxation term is negligible after very short times (on the order of $10^{-7} \mathrm{~s}$ for representative values of $E, m$ and $A, e . g$., for $E=200 \mathrm{GPa}, m \approx 0.4, A=10^{-15} \mathrm{~s}^{-1} \mathrm{~Pa}^{-1 / \mathrm{m}}$ and an initial stress $\sigma_{0} \approx 100 \mathrm{MPa}$ ). ${ }^{20)}$ From a mechanistic point of view, the irrelevance of the plastic relaxation term implies that the characteristic relaxation times corresponding to the operative micro-mechanistic processes are small in comparison with the period of the strain rate oscillations. Consequently, on the acceptance of such simplification, equation (6) yields

$$
m \ddot{\varepsilon} \approx \frac{\dot{\varepsilon}}{\sigma}\left(\frac{d \sigma}{d t}-\left.\frac{\partial \sigma}{\partial \varepsilon}\right|_{\dot{\varepsilon}} \dot{\varepsilon}\right)
$$

Then, the strain rate sensitivity $m$ can be calculated from the curve $\frac{\dot{\varepsilon}}{\sigma}\left(\frac{d \sigma}{d t}-\left.\frac{\partial \sigma}{\partial \varepsilon}\right|_{\dot{\varepsilon}} \dot{\varepsilon}\right)$ vs. $\ddot{\varepsilon}$. Figure 4 shows two representative examples of such plots. The plots contain the whole tests, i.e., many cycles in both cases. The cycles approximately collapse in a straight line crossing the origin for the low frequencies (weak or no hysteresis), thus indicating the validity of eq. (4), i.e., a simple power-law behaviour. For high frequencies, on the contrary, clear hysteresis cycles are 


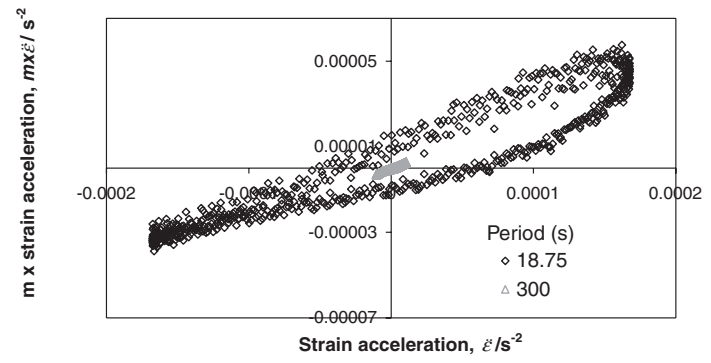

Fig. 4 Strain rate sensitivity times strain acceleration $v s$. strain acceleration for two tests with continuous change in strain rate, at $975^{\circ} \mathrm{C}$ and oscillation periods of 18.75 and $300 \mathrm{~s}$.

observed. In Fig. 4, several cycles are superposed for each testing condition. The individual cycles corresponding to each single oscillation do not significantly shift or change, indicating that the structure (e.g., grain size) does not significantly change during the tests.

As a consequence of the observed hysteresis, applying eq. (8) locally to the individual points of the strain rate cycles, an increasing dependence of the instantaneous value of the strain rate sensitivity $m$ on the strain acceleration and on the increase or decrease of the acceleration is observed for high oscillation frequencies. This behaviour and its possible structural origins are discussed below (see also Ref. 21)).

Neglecting for the moment the transient behaviour along each cycle and averaging the instantaneous strain rate sensitivity for cycles at several strain levels, plots of the average strain rate sensitivity $v s$. frequency can be obtained for each temperature and strain, as shown in Fig. 5 (recall that all the oscillating tests correspond to the same strain rate neighbourhood, $10^{-3} \mathrm{~s}^{-1}$ ). The results show only a very weak or negligible dependence of $m$ on the frequency of the strain rate oscillations or on the strain level. These results, obtained with the new method presented in this paper, agree very well with those measured with the traditional procedure for the same strain rate base (Fig. 3); they are also superposed in Fig. 5 (the frequency spectrum of their strain rate changes has a main peak in $9.4 \times 10^{-3} \mathrm{~s}^{-1}$ ).

\subsection{Response in terms of amplitude and phase shift}

Assuming a sinusoidal flow stress output as a response to the imposed sinusoidal perturbation of the strain rate, the material response in the oscillating strain rate tests can be treated in terms of amplitude and phase shift as

$$
\sigma=\sigma_{\text {base }}+\Delta \sigma \cos (\omega t+\delta)
$$

The flow stress response can be well approximated using a sinusoidal fitting, as shown in Fig. 6. Figures 7 and 8 show, respectively, the amplitude and the phase shift of the flow stress oscillation at four temperatures. In the temperature range between 925 and $975^{\circ} \mathrm{C}$ the stress amplitude weakly decreases as the frequency increases, without any strong peak indicative of intense activity of any particular mechanism. The error of each point is about $2 \mathrm{MPa}$. However, at $1000^{\circ} \mathrm{C}$ there is a distinct amplitude drop at low frequencies.

The effect of frequency on the phase shift of the flow stress is strong, the delay of the response increasing for increasing frequencies. Again a different behaviour is detected at
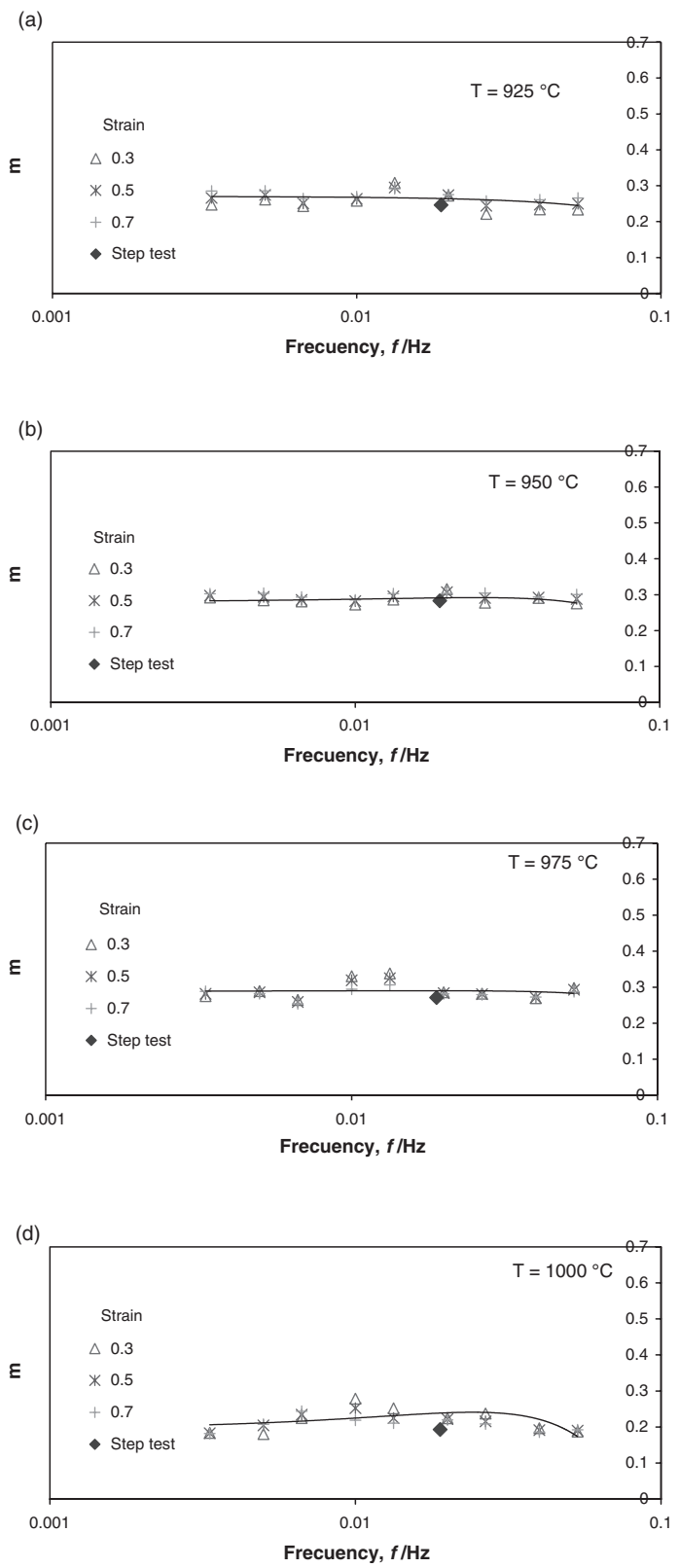

Fig. 5 Strain rate sensitivity for oscillating strain rate tests. The basis strain rate is $10^{-3} \mathrm{~s}^{-1}$. The solid diamond corresponds to the step test, which is related to the peak frequency $9.4 \times 10^{-3} \mathrm{~s}^{-1}$. (a) $925^{\circ} \mathrm{C}$, (b) $950^{\circ} \mathrm{C}$, (c) $975^{\circ} \mathrm{C}$, (d) $1000^{\circ} \mathrm{C}$.

$1000^{\circ} \mathrm{C}$ and low frequencies (below $10^{-2} \mathrm{~Hz}$ ).

It is also interesting to visualize the response to the input signal by representing the strain rate $v s$. stress for an oscillation cycle, see Fig. 9. The sign and magnitude of the phase shift can be inferred from the shape of the cycle. With the axis convention of the figure, negative phase shifts correspond to a clockwise rotation sense along the cycle, while positive phase shifts involve an anti-clockwise rotation. Figure 9 shows two of such cycles where the rotation is clockwise and the hysteresis increases as the frequency increases. This result is common for all the performed tests.

\subsection{Effect of strain acceleration}

An attempt to characterise the dependence of the stress response on strain acceleration is based on a modification of 


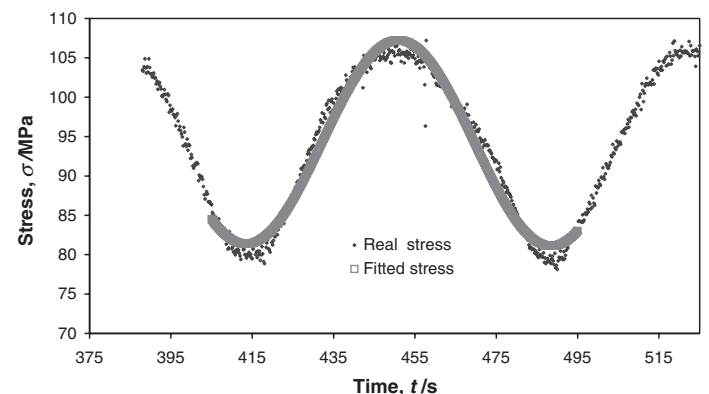

Fig. 6 Fitting between real tensile stress and a sinusoidal stress.
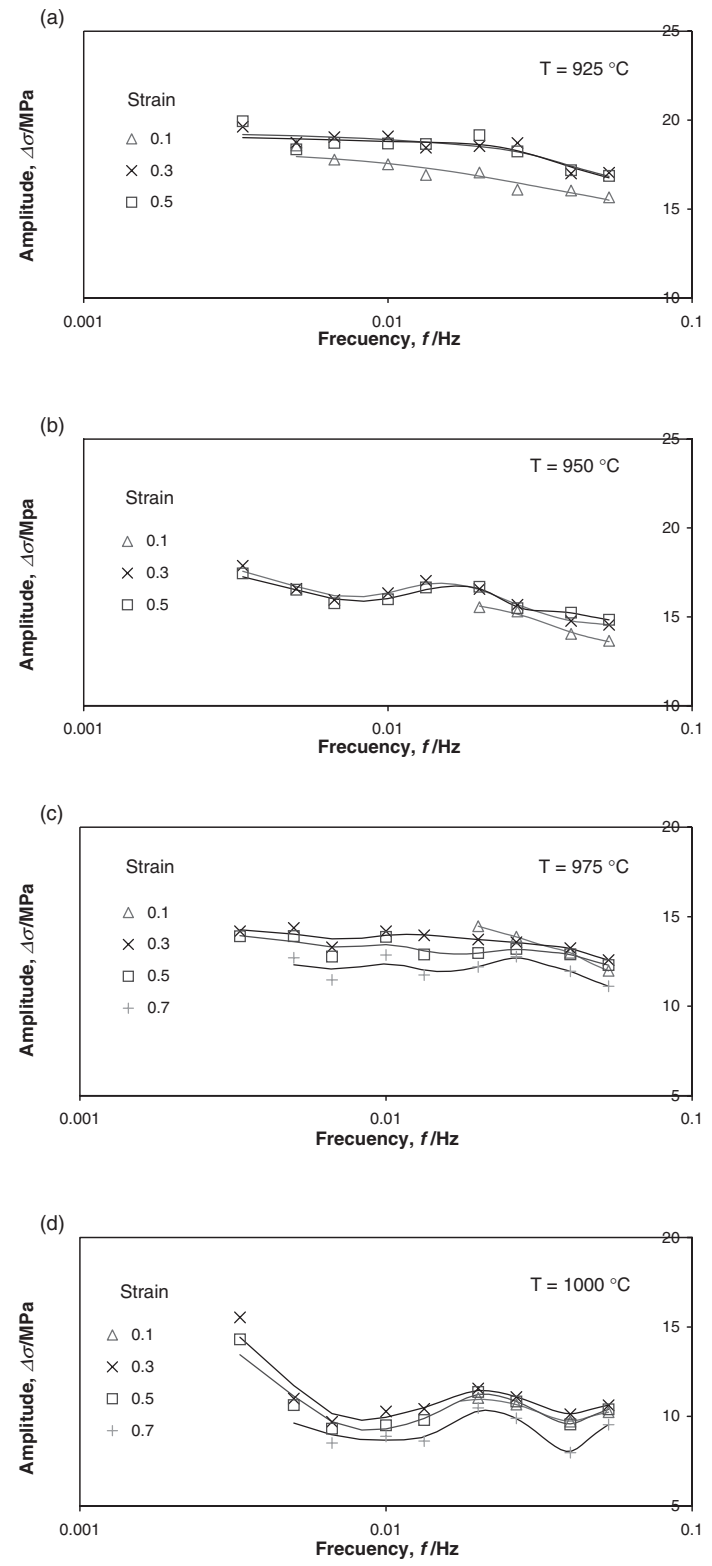

Fig. 7 Amplitude of the stress response in the oscillating strain rate tests. (a) $925^{\circ} \mathrm{C}$, (b) $950^{\circ} \mathrm{C}$, (c) $975^{\circ} \mathrm{C}$, (d) $1000^{\circ} \mathrm{C}$. Fitting has been performed with $\beta$-splines.

eq. (4) that assumes an explicit dependence on the strain acceleration as

$$
\sigma=F(\ddot{\varepsilon}) \dot{\varepsilon}^{m(\ddot{\varepsilon})}
$$
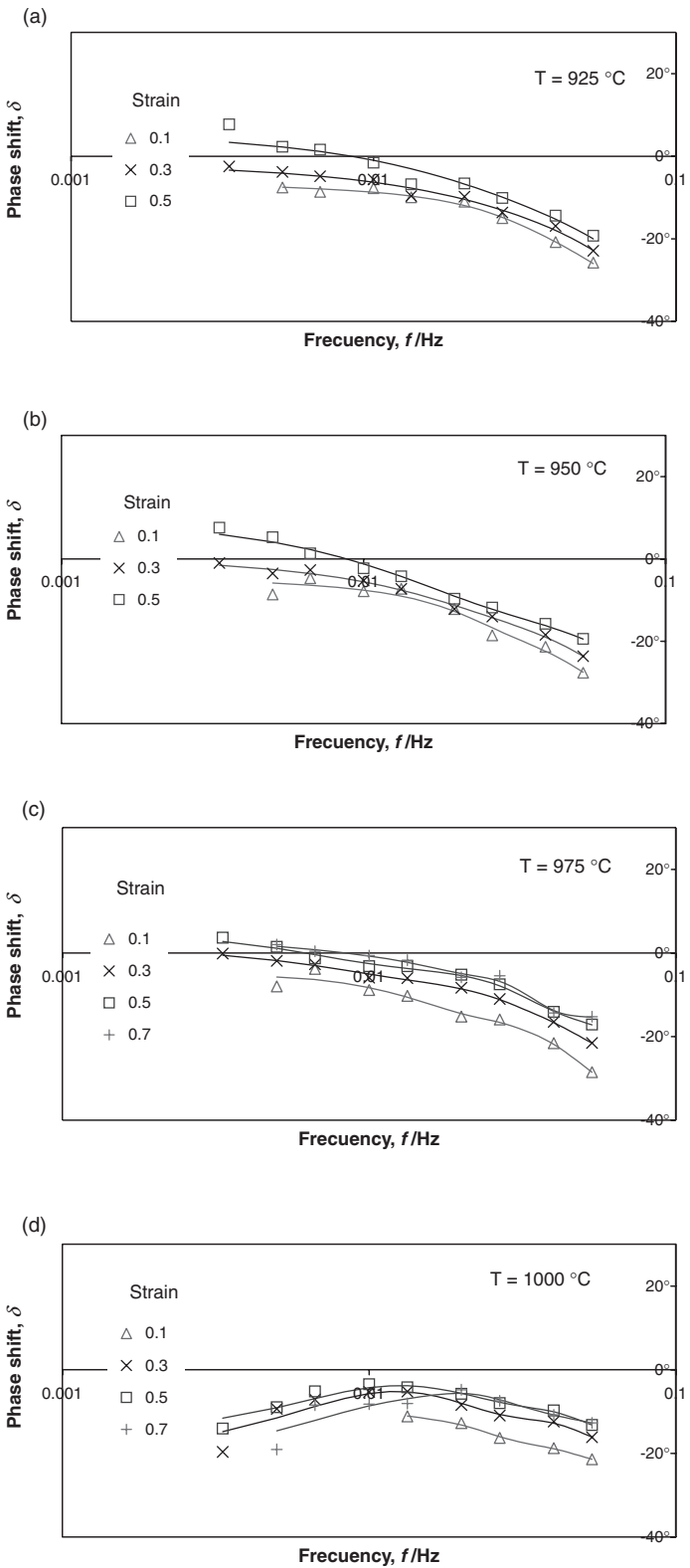

Fig. 8 Phase shift of the stress response in the oscillating strain rate tests. (a) $925^{\circ} \mathrm{C}$, (b) $950^{\circ} \mathrm{C}$, (c) $975^{\circ} \mathrm{C}$, (d) $1000^{\circ} \mathrm{C}$. Fitting has been performed with $\beta$-splines.

Values of the strain rate sensitivity $m(\ddot{\varepsilon})$ for several strain accelerations have been obtained from plots of $\sigma(\dot{\varepsilon})$ vs. $\dot{\varepsilon}$ at constant $\ddot{\varepsilon}$ (strain averaged). These are shown in Fig. 10. A slight increase of the strain rate sensitivity as strain acceleration increases is clearly observed for the four studied temperatures.

\subsection{Deformation textures}

The crystallographic textures of the as-received INCONEL 718SPF material and of several superplastically deformed specimens analysed using the Electron Back-Scattered Diffraction (EBSD) technique are presented below.

In order to assess the role played by crystallographic slip in the superplastic deformation of the alloy, the virtual evolution of the experimental texture of the undeformed material has been numerically simulated using a "full constraints" Taylor code on the assumption that deformation 
(a)

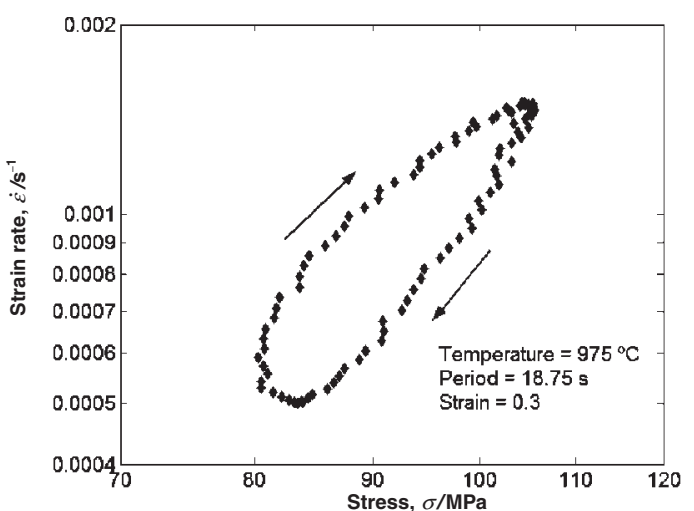

(b)

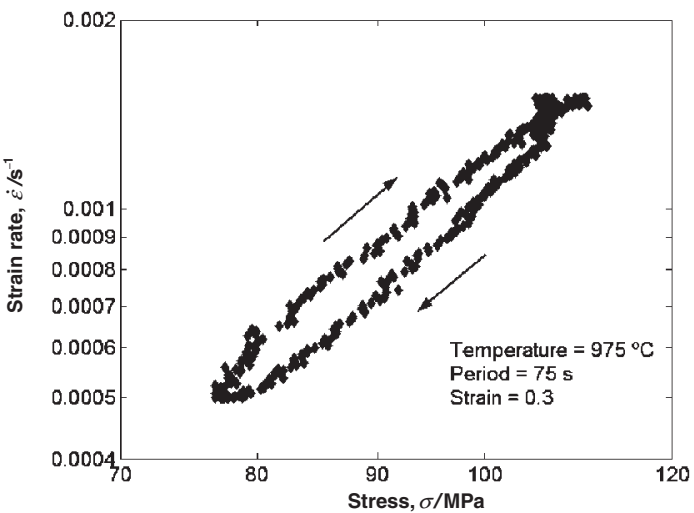

Fig. 9 Strain rate as a function of stress for a cycle of oscillation. Tests performed at $975^{\circ} \mathrm{C}$. Approximate strain 0.3 with oscillation periods (a) $18.75 \mathrm{~s}$ and (b) $75 \mathrm{~s}$

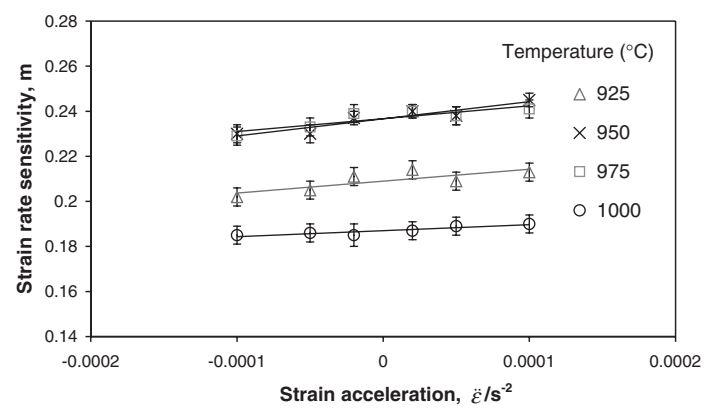

Fig. 10 Strain rate sensitivity, $m$, as a function of strain acceleration. Values for oscillating strain rate tests, with a base strain rate of $10^{-3} \mathrm{~s}^{-1}$ and temperatures between 925 and $1000^{\circ} \mathrm{C}$.

occurs exclusively by $\{111\}\langle 110\rangle$ slip. The software used in the simulations was the MTM-Taylor v.2 program, developed by the Catholic University of Leuven. ${ }^{22)}$ Measured and calculated densities of the $\alpha$ and $\beta$ fibres (main components of rolled and recrystallized fcc sheets) are shown in Fig. 11. The textures after a strain of 0.8 at 975 or $1000^{\circ} \mathrm{C}$ are weaker than the initial texture, an indication that non-crystallographic deformation mechanisms (grain boundary sliding) play a significant role. However the final measured textures are not a mere attenuation of the initial texture: distinct relative intensity changes have occurred along the $\alpha$ and $\beta$ fibres. For the samples deformed at $975^{\circ} \mathrm{C}$ (high degree of GBS superplasticity), the changes can be approximately
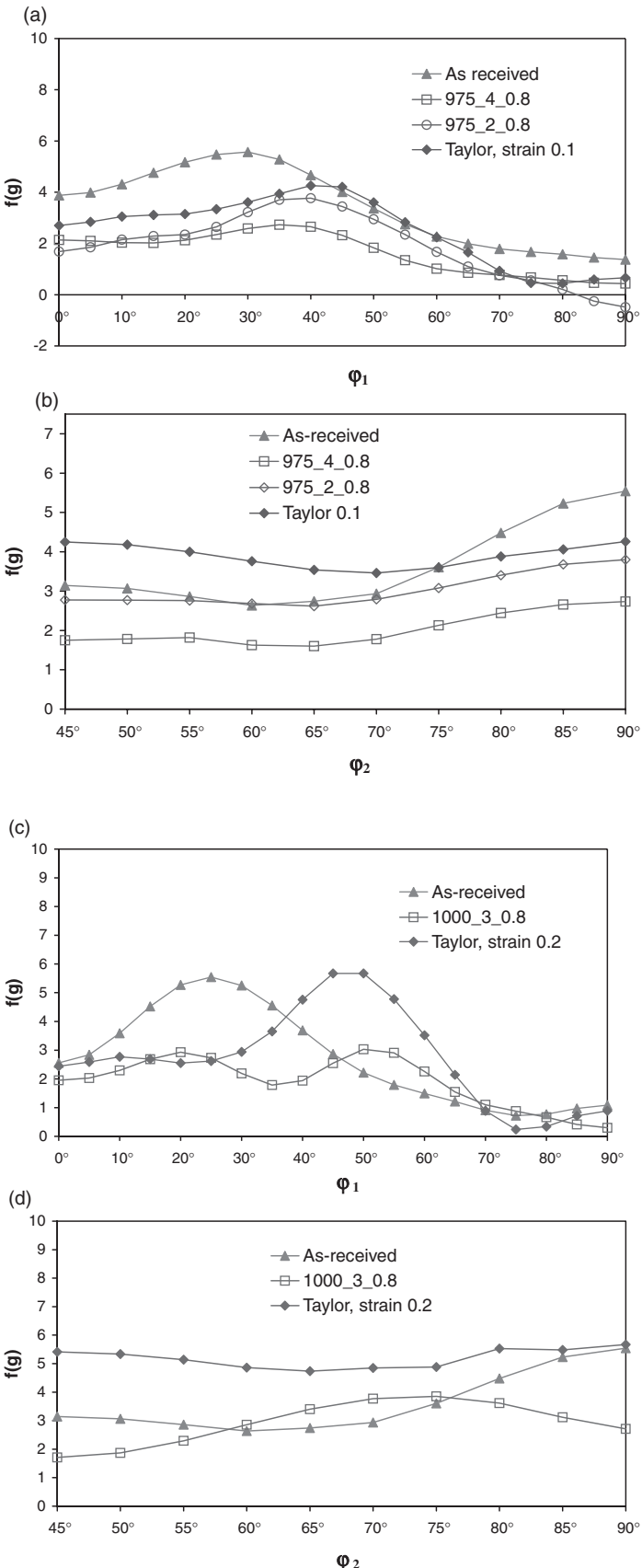

Fig. 11 (a) $\alpha$ fibre and (b) $\beta$ fibre for a test performed at $975^{\circ} \mathrm{C}$ and at strain rates $10^{-4}$ and $10^{-2} \mathrm{~s}^{-1}$ compared to the fibres of the as-received material and the Taylor simulation for a strain 0.1. (c) $\alpha$ fibre and (d) $\beta$ fibre for a test performed at $1000^{\circ} \mathrm{C}$ and $10^{-3} \mathrm{~s}^{-1}$, compared to the fibres of the asreceived material and the Taylor simulation for a strain 0.2. In all cases, the reached strain is 0.8 .

described by superposition of $50 \%$ random texture, $25 \%$ asreceived texture and $25 \%$ initial texture modified by a small elongation strain $(10 \%)$ by crystallographic $\{111\}\langle 110\rangle$ slip (Fig. 12). For the samples deformed at $1000^{\circ} \mathrm{C}$, the fitting is not satisfactory; the discrepancy can be due to grain growth.

\section{Discussion}

\subsection{The limited strain rate sensitivity of the $718 \mathrm{SPF}$ alloy}

It has been mentioned above that strain rate sensitivities, 
(a)

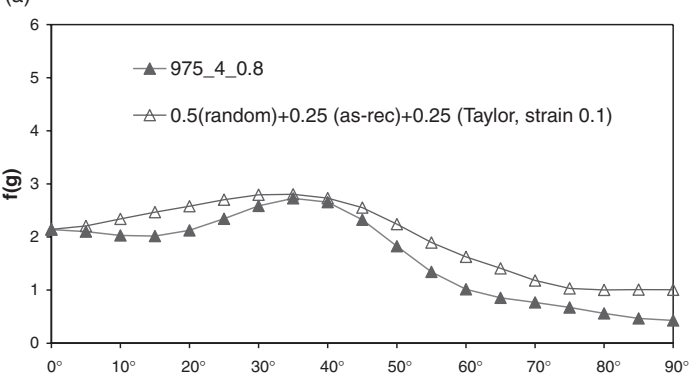

(b)

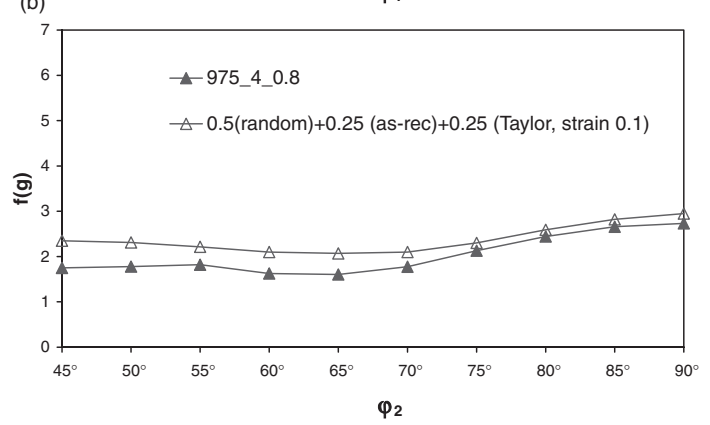

(c)

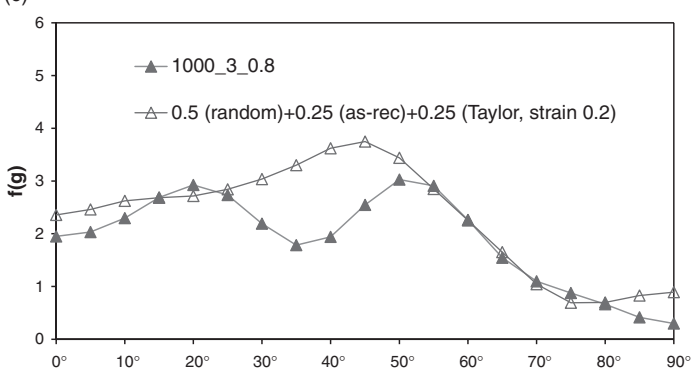

(d)

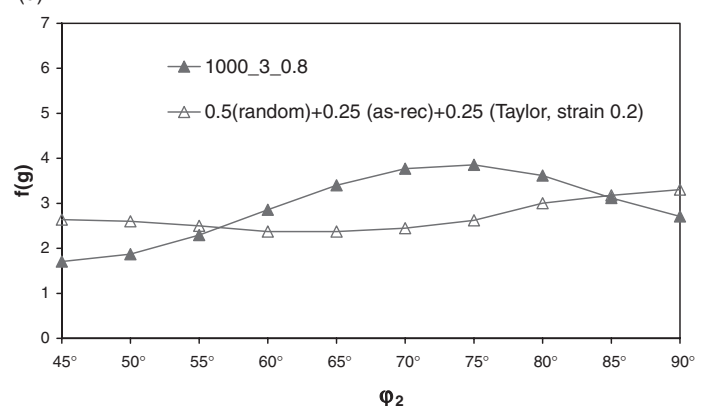

Fig. 12 Fibres for a test performed at $975^{\circ} \mathrm{C}$ and strain rate $10^{-4} \mathrm{~s}^{-1}$, compared to a superposition of $50 \%$ random texture, $25 \%$ as-received texture, and $25 \%$ of the Taylor simulation for strain 0.1 : (a) $\alpha$ fibre, (b) $\beta$ fibre. The same for a test performed at $1000^{\circ} \mathrm{C}$ and strain rate $10^{-3} \mathrm{~s}^{-1}$ : (c) $\alpha$ fibre, (d) $\beta$ fibre.

$m$, in INCONEL 718 are low compared to standard values of other superplastic materials.

The presence of $\delta$ phase particles at the grain boundaries of the 718 alloy would make the contribution of intragranular deformation by crystallographic slip necessary for achieving strain rates above $10^{-4} \mathrm{~s}^{-1}$ and this would explain the relatively low $m$ values measured for this material. Chen and Chaturdevi ${ }^{8)}$ have analysed the effect of grain boundary precipitates of $\delta$ phase on creep properties of an INCONEL 718 with grain size of about $60 \mu \mathrm{m}$. Although their tests were performed at $625^{\circ} \mathrm{C}$, well below the temperatures studied in the present work (and thus out of the superplastic range), their study reveals the strong influence that $\delta$ precipitation on boundaries has on grain boundary sliding. The size of particles is critical and in their opinion stress concentration around small particles is relaxed by diffusion and by powerlaw dislocation creep for bigger particles. Other studies have pointed out that this argument can be extrapolated to the superplastic deformation region of fine grain INCONEL $718 .^{23)}$ The hindering or even the inhibition of GBS by grain boundary precipitates has been repeatedly observed in many superplastic materials. ${ }^{8,24-28)}$

The texture analysis performed in this work provides strong indications that crystallographic slip contributes not only to superplastic deformation of INCONEL 718 as an accommodation mechanism of the GBS main deformation process but also as an independent mechanism for the macroscopic deformation.

As mentioned above, deformation textures for several tests can be described as the attenuated sum of the as-received texture and the Taylor simulation for strains 0.1-0.2. Grain boundary sliding, acting alone, is related to a general attenuation of texture, without any change in main components. This can be explained by taking into account the grain rotation and rearrangement associated with grain boundary sliding: the randomness of this mechanism produces a randomisation of the texture. Deformation by crystallographic slip, on the contrary, is related to a sharpening of some texture components, and therefore, to a texture change. By contrast, crystallographic slip acting only as an accommodation mechanism, produces also a mere texture attenuation.

Consequently, crystallographic slip appears to contribute, as an independent mechanism, to the deformation of INCONEL 718, even in the conditions of the optimum superplasticity $\left(975^{\circ} \mathrm{C}, 10^{-4} \mathrm{~s}^{-1}\right)$. The main mechanism is, nevertheless, grain boundary sliding, as attested by the little apparent strain of the Taylor simulation that best fits the observed results. Moreover, grains remain equiaxed up to strains as high as 0.8 .

The relevance of crystallographic slip would be expected to increase with the grain coarsening that occurs at the highest temperatures studied in this work. This is in agreement with the results of the texture analysis (Fig. 12) and with the observed increase in flow stress at temperatures above $975^{\circ} \mathrm{C}$ [Fig. 2(a)].

The found activation energies, deduced from the flow stresses, also reinforce the hypothesis of an important dislocation creep activity. The calculated activation energy is about $380 \mathrm{~kJ} / \mathrm{mol}$ (Table 2); this value agrees better with values reported for volume self-diffusion energies (257$\left.357.4 \mathrm{~kJ} / \mathrm{mol}^{15)}\right)$ than with grain boundary self-diffusion energies $\left(118.2 \mathrm{~kJ} / \mathrm{mol}^{15)}\right)$.

In conclusion, the observed activation energies, textures and strain rate sensitivity values reflect the relevance of crystallographic slip in the superplastic deformation of Inconel 718SPF. Coexistence of crystallographic slip and grain boundary sliding has been observed in superplastic deformation of other alloys too (e.g., $\mathrm{Al}$ alloys ${ }^{29)}$ ). 
Table 2 Activation energies for superplastic deformation of INCONEL 718.

\begin{tabular}{|c|c|c|c|}
\hline $\begin{array}{c}\text { Temperature } \\
\left({ }^{\circ} \mathrm{C}\right)\end{array}$ & Region & $\begin{array}{l}\text { Activation energy } \\
\qquad(\mathrm{kJ} / \mathrm{mol})\end{array}$ & Reference \\
\hline $900-945$ & & 179.3 & Kashyap and \\
\hline $945-975$ & & 345.4 & Chaturdevi $^{15)}$ \\
\hline \multirow[t]{2}{*}{$900-950$} & II & 308 & Kashyap and \\
\hline & III & 353 & Chaturdevi $^{23)}$ \\
\hline 950-980 & & $345 \pm 20$ & \multirow{2}{*}{ Huang et al. ${ }^{12)}$} \\
\hline$>1010$ & & $433 \pm 50$ & \\
\hline $925-975$ & & 380 & This work \\
\hline
\end{tabular}

\subsection{Transient strain rate effects}

Studies of the effect of strain rate transients on the plastic behaviour of superplastic metals are scarce in the literature, ${ }^{30,31)}$ although the cases of hot working ${ }^{32-35)}$ and creep $^{36-39)}$ conditions have been investigated more extensively. One common observation in the hot-working or creep studies is that conventional materials react to strain rate transients according to two typified behaviours: either "pure metal" or "alloy" type. The flow stress of "pure metals" in an increasing (decreasing) strain rate change is smaller (greater) than the flow stress corresponding to the same strain rate in a constant strain rate test (secondary creep or steady state deformation tests). This phenomenon is commonly interpreted as a control of the old dislocation structure, which needs a finite deformation transient to be adjusted to the structure required at the new strain rate. Alloys behave in the opposite manner, and this is explained by the control of the transient flow stress by the mobile dislocation density that cannot immediately adjust to the value that would take in a constant strain rate situation.

If this behaviour is described in terms of phase shifts, "pure metal" behaviour would be related to negative phase shifts, whilst "alloy type" behaviour would correspond to positive phase shifts. In our case, the main observed behaviour corresponds to negative phase shift, thus, "pure metal" behaviour. Nevertheless, also positive phase shifts (corresponding to "alloy type" behaviour) have been observed at the lowest oscillation frequencies and in the temperature range between 925 and $975^{\circ} \mathrm{C}$. The very small value of this positive phase shifts forces to see these results with caution, because the experimental error could be responsible for them.

The fact that this alloy has shown a behaviour similar to the "pure metal" creep behaviour in almost all the range of temperature and strain rate studied may be surprising. However, such a phenomenology seems to be common for fine-grained superplastic metals: Zhang et al. ${ }^{30)}$ and Booeshaghi and Garmestani ${ }^{31)}$ observed the same "pure metal" type response to transients during instantaneous strain rate change or relaxation tests of, respectively, $\mathrm{Pb}-\mathrm{Sn}$ eutectic and Al-Li 8090 alloy in the superplastic regime. Control by the old dislocation structure seems to be an inappropriate explanation for the transient behaviour of superplastic materials. Anelastic strain (recoverable, time dependent, non-linear strain) is a more plausible way of explaining the observed results, as pointed out by Booeshaghi and Garmes- $\operatorname{tani}^{31)}$ or Schneibel and Hazzledine, ${ }^{40)}$ who even coined the term superanelasticity in view of the big ratio of anelastic to elastic recoverable strains observed in the discharge of superplastically deforming materials. Todd ${ }^{41)}$ and Wakai et $a l .{ }^{42)}$ have proposed that back stress boundary tension could make an important contribution to the extraordinary anelastic recovery observed in superplastic materials.

\section{Conclusions}

(1) The tensile deformation of INCONEL 718 SPF has been studied in the temperature and strain rate ranges of 925-1000 ${ }^{\circ} \mathrm{C}$ and $10^{-4}-10^{-2} \mathrm{~s}^{-1}$. Conventional (instantaneous) and continuous strain rate change tests have been performed. The strain rate sensitivity exponent $m$ can be measured using both types of tests but tests analysing the response to continuous strain rate changes give valuable additional information about the transient response.

(2) Measured strain rate sensitivities are similar in both types of tests and for all the oscillation frequencies studied. However, continuous strain rate changes show that the strain rate sensitivity depends on strain acceleration: its value is slightly lower for negative than for positive strain accelerations.

(3) The evolution of INCONEL 718 texture as superplastic deformation goes on and its comparison with Taylortype deformation texture simulations show that crystallographic slip is here a secondary but independent deformation process and not a mere accommodation mechanism of grain boundary sliding. This explains the modest $m$ values of this alloy.

(4) Superplastic INCONEL 718 shows significant strain rate transient effects. The behaviour of the strain rate $v s$. stress curves for each cycle of oscillation is like that observed in pure metals creep (non-superplastic deformation). These effects are explained by the great anelasticity observed in fine grained superplastically deforming materials.

\section{Acknowledgements}

The authors acknowledge partial support of this work from the Department of Industry of the Basque Government (project DT-ITP-98-001). The project was carried out in cooperation with ITP (Industria de Turbo Propulsores), Zamudio, Spain. The authors wish to thank Dr. K. Ostolaza from ITP for providing the material studied in this work and for his collaboration and discussions all along the project.

\section{REFERENCES}

1) C. P. Ling, Y. Estrin and P. G. McCormick: Acta Metall. Mater. 42 (1994) 1541-1549.

2) H. W. Song, S. R. Guo, D. Z. Lu, Y. Xu, Y. L. Wang and D. L. Lin: Scr. Mater. 42 (2000) 917-922.

3) A. A. Guimaraes and J. J. Jonas: Metall. Trans. 12A (1981) 1655-1666.

4) M. S. Lewandowski and R. A. Overfelt: Acta Mater. 47 (1999) 46954710 .

5) N. Srinivasan and Y. V. R. K. Prasad: Metall. Mater. Trans. A 25 (1994) 2275-2284. 
6) S. V. S. Narayana Murty and B. Nageswara Rao: Mater. Sci. Eng. A 254 (1998) 76-82.

7) S. C. Medeiros, Y. V. R. K. Prasad, W. G. Frazier and R. Srinivasan: Mater. Sci. Eng. A 293 (2000) 198-207.

8) W. Chen and M. C. Chaturdevi: Mater. Sci. Eng. A 183 (1994) 81-89.

9) W. Chen and M. C. Chaturdevi: Acta Mater. 45 (1997) 2735-2746.

10) L. X. Zhou and T. N. Baker: Mater. Sci. Eng. A 177 (1994) 1-9.

11) G. D. Smith and D. H. Yates: Superalloys 92, ed. by S. D. Antolovich, R. W. Stusrud, R. A. MacKay, D. L. Anton, T. Khan, R. D. Kissinger and D. L. Klarstrom (The Minerals, Metals \& Materials Society, 1992) p. 43.

12) Y. Huang, M. Strangwood and P. L. Blackwell: Mater. Sci. Tech. 16 (2000) 1309-1313.

13) M. S. Yeh, C. W. Tsau and T. H. Chuang: J. Mater. Eng. Perfor. 5 (1996) 71-77.

14) C. L. Hale, W. S. Rollings and M. L. Weaver: Mater. Sci. Eng. A 300 (2001) 153-164.

15) B. P. Kashyap and M. C. Chaturdevi: Scr. Mater. 43 (2000) 429-433.

16) Y. Huang and P. L. Blackwell: Mater. Sci. Tech. 18 (2002) 1104-1108.

17) H. Lu, X. Jia, K. Zhang and C. Yao: Mater. Sci. Eng. A 326 (2002) 382-385.

18) Y. Huang and P. L. Blackwell: Mater. Sci. Tech. 19 (2003) 461-466.

19) H. Xue, W. Lijun, X. Hui, L. Runguang, W. Shaogang and C. Zhonglin: J. Mater. Proc. Technol. 137 (2003) 17-20.

20) M. Urdanpilleta: Doctoral dissertation, TECNUN, University of Navarra, San Sebastian, Spain, 2003.

21) M. Urdanpilleta and J. Gil Sevillano: Mater. Lett. 58 (2004) 30523057.

22) P. Van Houtte: The "MTM-FHM" Software System Version 2 Manual, (Department of Metallurgy and Materials Engineering, Katholieke Universiteit Leuven, Belgium, 1994, updated 1995).

23) B. P. Kashyap and M. C. Chaturdevi: Mater. Sci. Tech. 16 (2000) 147-
155.

24) H. J. Murphy, C. T. Sims and G. R. Heckman: Trans. Metall. Soc. AIME 239 (1967) 1961-1978.

25) W. Betteridge and A. W. Franklin: J. Inst. Met. 85 (1957) 473-479.

26) H. E. Collins: Metall. Trans. 5 (1975) 189-204.

27) C. A. P. Horton: Acta Metall. 20 (1972) 477-479.

28) C. A. P. Horton: Scr. Metall. 8 (1974) 1-6.

29) M. T. Pérez-Prado, M. C. Cristina, O. A. Ruano and G. GonzálezDoncel: Mater. Sci. Eng. A 244 (1998) 216-223.

30) K. Zhang, C. H. Hamilton, H. M. Zbib and M. Khraisheh: Scr. Metall. Mater. 32 (1995) 919-924.

31) F. Booeshaghi and H. Garmestani: Scr. Mater. 40 (1999) 509-516.

32) J. J. Urcola and C. M. Sellars: Acta Metall. 35 (1987) 2637-2647.

33) J. J. Urcola and C. M. Sellars: Acta Metall. 35 (1987) 2649-2657.

34) J. J. Urcola and C. M. Sellars: Acta Metall. 35 (1987) 2659-2669.

35) G. J. Baxter, T. Furu, Q. Zhu and J. A. Whiteman: Sellars C. M., Acta Mater. 47 (1999) 2367-2376.

36) D. L. Yaney, J. C. Gibeling and W. D. Nix: Acta Mater. 35 (1985) 1391-1400

37) W. Blum: in Plastic Deformation and Fracture of Materials, ed. by H. Mughrabi, vol. 6, Materials Science and Technology. A Comprehensive Treatment, ed. by R. W. Cahn, P. Haasen and E. J. Kramer (VCH, Weinheim, Germany, 1993) p. 359.

38) W. Blum: Mater. Sci. Eng. A 319 (2001) 8-15.

39) W. Blum, P. Eisenlohr and F. Breutinger: Metall. Mater. Trans. A 33 (2002) 291-303.

40) J. H. Schneibel and P. M. Hazzledine: Acta Metall. 30 (1982) 12231230.

41) R. I. Todd: Acta Metall. Mater. 42 (1994) 2921-2928.

42) F. Wakai, Y. Shinoda, S. Ishihara and A. Domínguez-Rodríguez: Acta Mater. 50 (2002) 1177-1186. 